\title{
Bone mineral density in professional female dancers
}

\author{
N Keay, I Fogelman, G Blake
}

\begin{abstract}
Objectives-To measure the long term effects of dance training and the contribution of the timing and duration of any menstrual disruption on bone mineral density (BMD).
\end{abstract}

Design-Measurement of BMD in 57 premenopausal, previously professionally dance trained women and the relationship to menstrual and training history.

Main outcome measures-Bone density measurements at lumbar spine and femoral neck by dual energy $x$-ray absorptiometry.

Results-The average $\mathrm{Z}$ score for $\mathrm{BMD}$ at the lumbar spine in the amenorrhoeic dancers was significantly below that for the normal population. The average $Z$ score for BMD at the femoral neck in the eumenorrhoeic dancers was significantly above that for the normal population. There was a significant difference between the average $Z$ score for $B M D$ at both the lumbar spine and femoral neck between the amenorrhoeic and eumenorrhoeic dancers. Significant negative relationships were found between BMD at the lumbar spine and (1) age at menarche, (2) duration of amenorrhoea, (3) BMD at the femoral neck, and (4) the variable of ideal minus lowest weight, which was independent of amenorrhoea. No significant relationships were found between duration of oral contraceptive pill usage and BMD at either the lumbar spine or the femoral neck in eumenorrhoeic or amenorrhoeic dancers. In order to quantify the effect of a combination of these significant factors, a model of BMD was constructed using multiple regression incorporating the variables duration of amenorrhoea, age at menarche, and ideal minus lowest body weight. In this model $R^{2}$ was $33.6 \%$, in other words $33.6 \%$ of the total variation in the $Z$ score for BMD at the lumbar spine could be accounted for by these factors. Conclusion-Professional female dancers with a history of delayed menarche and amenorrhoea have been identified as another group of premenopausal women potentially at risk of developing osteoporosis because of a decrease in BMD at the lumbar spine. The femoral neck in dancers with a history of amenorrhoea was partially protected from loss of BMD by virtue of being the major weight bearing site in previous dance training, and in eumenorrhoeic dancers BMD was significantly increased at this site. (Br f Sports Med 1997;31:143-147)

Keywords: dance training; amenorrhoea; menarche; bone mineral density

Osteoporosis is a common condition, usually occurring in postmenopausal women, and is accompanied by significant morbidity and mortality. Prediction of those at risk is therefore important in order for preventive measures to be instituted.

Although weight bearing exercise increases bone mineral density (BMD), intense training coupled with an energy restricted diet may result in amenorrhoea in young women: one third of professional dancers are amenorrhoeic. ${ }^{2}$ This hypo-oestrogenic state outweighs the benefit of exercise, and a reduction in BMD is seen in amenorrhoeic women in training, compared with their eumenorrhoeic counterparts, a phenomenon originally described ten years $\mathrm{ago}^{3}$ and now well established. ${ }^{4}$

Reduced BMD in such exercising amenorrhoeic women can result in an immediate risk of fracture. ${ }^{5}$ This leads to the hypothesis that, if the reduction in $\mathrm{BMD}$ is irreversible, then there may exist an increased risk of early osteoporosis in later life. However, until now no studies have been possible to assess fully the long term effects on BMD, as athletic amenorrhoea is a relatively new phenomenon associated with recent increased training levels in women. Studies have therefore concentrated on young women still in training, with a short follow up period: 15 months ${ }^{6}$ and 24 months. Although BMD has been measured in a small group of 14 older retired dancers, ${ }^{8}$ menstrual and dance training history were not recorded, so the long term effect of amenorrhoea or any other relevant factors on BMD later in a dancer's career has not yet been assessed.

The aim of the present study was to quantify the long term effects of dance training and the contribution of the timing and duration of any menstrual disruption on BMD in order to identify whether any aspects of such training may influence the risk of developing osteoporosis. This was achieved by measuring BMD in a group of professionally trained female ballet dancers and relating the measurements to menstrual and training history.

\section{Methods}

A group of 57 women who had followed professional dance careers were studied. All 
Table 1 Demographic details of subjects; range in parentheses

\begin{tabular}{|c|c|c|c|c|}
\hline & All subjects & $\begin{array}{l}\text { Amenorrhoeic } \\
\text { subjects }\end{array}$ & $\begin{array}{l}\text { Eumenorrhoeic } \\
\text { subjects }\end{array}$ & $\begin{array}{l}\text { Oligomenorrhoeic } \\
\text { subjects }\end{array}$ \\
\hline $\begin{array}{l}\text { Number } \\
\text { No of classical dancers } \\
\text { No of contemporary dancers } \\
\text { Curent age (years) } \\
\text { Age at menarche (years) } \\
\text { Length of career (years) } \\
\text { Years since retiring } \\
\text { No still dancing } \\
\text { Current weight (kg) } \\
\text { Current height (cm) } \\
\text { Ideal - lowest weight (kg) } \\
\text { No taken OCP`} \\
\text { Duration of OCP (years) } \\
\text { Average } Z \text { score for BMD at lumbar spine } \\
\text { Average } Z \text { score for BMD at femoral neck }\end{array}$ & $\begin{array}{l}57 \\
48 \\
9 \\
36(25-50) \\
13.5 \\
11.1(3-29) \\
9.6(0-26) \\
7 \\
55 \\
164 \\
10.5 \\
35 \\
3.5(0.5-27) \\
-0.19 \\
0.148\end{array}$ & $\begin{array}{l}38 \\
34 \\
4 \\
35(23-50) \\
13.8 \\
10.8(4-23) \\
8.7(0-30) \\
7 \\
54 \\
163 \\
11.3 \\
23 \\
2.5(0.5-27) \\
-0.49 \\
-0.07\end{array}$ & $\begin{array}{l}12 \\
12 \\
0 \\
40(31-49) \\
13 \\
12.5(6-29) \\
13.7(5-26) \\
0 \\
57 \\
164 \\
8.8 \\
9 \\
8(1-24) \\
0.2 \\
0.77\end{array}$ & $\begin{array}{l}7 \\
2 \\
5 \\
34(26-44) \\
13.4 \\
10.6(3-23) \\
7.4(5-17) \\
0 \\
55 \\
166 \\
8.7 \\
3 \\
1.4(1-5) \\
0.79 \\
0.28\end{array}$ \\
\hline
\end{tabular}

$\star \mathrm{OCP}=$ oral contraceptive pill.

were premenopausal, with a minimum age of 23 years. Women were excluded if they had undergone an hysterectomy and/or oophorectomy, suffered any significant diseases, or received any treatment likely to affect calcium metabolism (apart from the oral contraceptive pill).

All the women had BMD scans of the lumbar spine and femoral neck on a Hologic QDR-2000 bone densitometer. In addition, they were all interviewed by questionnaire to obtain information on dance training, weight changes, and menstrual pattern.

The relationship of dance training and menstrual pattern to $Z$ score for $B M D$ were assessed assuming the null hypothesis and using a one sided $t$ test. Results with $\mathrm{P}$ values less than 0.05 were considered to be significant. The $\mathrm{Z}$ score for $\mathrm{BMD}$ was used, as this is an age matched measure and thus the relative value for dancers of different ages could be compared. Multiple regression analysis was then used to build a model incorporating the significant variables found to influence the $Z$ score for BMD.

\section{Results}

Table 1 shows the demographic details of the subjects, classified according to menstrual status. The criterion for amenorrhoea was absence of periods for more than 3 months, and the criterion for oligomenorrhoea a cycle of more than 32 days. ${ }^{9}$

The important results are that the majority of dancers were classical (ballet) dancers and 50 of the total of 57 had retired an average of 9.6 years previously, with a current average age of 36 years.

Comparing the different menstrual groups, the dancers who had experienced amenorrhoea during their careers had also experienced the greatest decrease from their ideal weight. Considering the bone density results, the following were significant. (1) The average $Z$ score for

Table 2 Amenorrhoeic subjects, range in parentheses

\begin{tabular}{ll}
\hline Number & 38 \\
Number with continuous amenorrhoea & 34 \\
Number with episodic amenorrhoea & 4 \\
Average length of amenorrhoea (years) & $3.5(05-13)$ \\
Number still amenorrhoeic & 5 \\
Number still amenorrhoeic and in training & 5 \\
Average number of years since amenorrhoeic & $12.6(0-29)$
\end{tabular}

$\mathrm{BMD}$ at the lumbar spine in the amenorrhoeic dancers was significantly below that for the normal population $(P<0.01)$. The average $Z$ score for BMD at the femoral neck of these dancers was not significantly different from that of the normal population. (2) The average $\mathrm{Z}$ score for $\mathrm{BMD}$ at the femoral neck in the eumenorrhoeic dancers was significantly above that for the normal population $(P<0.01)$. The average $\mathrm{Z}$ score for $\mathrm{BMD}$ at the lumbar spine of these dancers was not significantly different from that of the normal population. (3) Comparing the amenorrhoeic and eumenorrhoeic dancers, there were significant differences in the average BMD measurements at both sites. The average $Z$ score for $B M D$ at the lumbar spine in the amenorrhoeic dancers was significantly lower than that for the eumenorrhoeic dancers $(P<0.025)$. Secondly, the average $Z$ score for $\mathrm{BMD}$ at the femoral neck in the eumenorrhoeic dancers was significantly higher than that for the amenorrhoeic dancers $(\mathrm{P}<0.025)$.

The small number of oligomenorrhoeic dancers made it difficult to analyse statistically and this will be considered in the Discussion.

Table 2 gives details of the 38 amenorrhoeic dancers. Most had experienced continuous amenorrhoea for an average of 3.5 years. The timing of the amenorrhoea related to when they had been in training, on average 12.6 years previously. Thus most had resumed normal menstruation at the time of the study, and the five dancers who continued to be amenorrhoeic were the only subjects in the whole study who were still dancing. Amenorrhoeic dancers who had taken the oral contraceptive pill had tended to do so after experiencing amenorrhoea.

Significant negative relationships were found between $B M D$ at the lumbar spine and the following. (1) Age at menarche $(P<0.01)$. This relationship was not significant for the femoral neck, although the trend at this site was in the same direction (fig 1). (2) Duration of amenorrhoea $(P<0.001)$ : one year of amenorrhoea resulted in a reduction in BMD by $0.1-0.2$ SDs, with $90 \%$ confidence. The trend at the femoral neck was in the same direction, but less pronounced $(P<0.005)$ (fig 2$)$. (3) The variable of ideal minus lowest body weight $(P<0.001)$. This relationship was not signifi- 


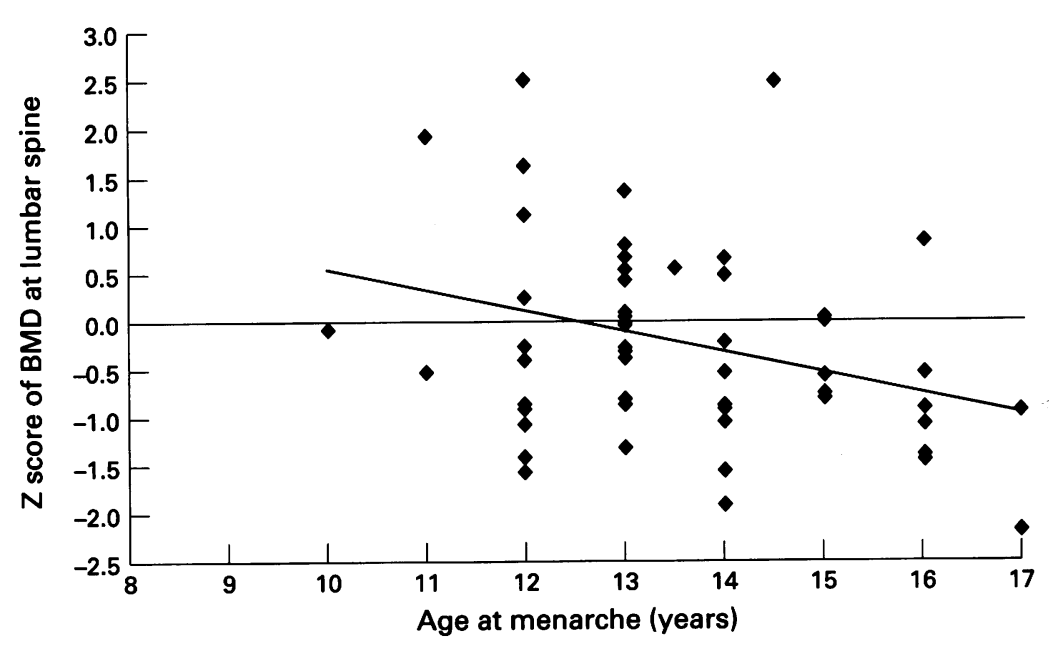

Figure $1 Z$ score of BMD at the lumbar spine plotted against age at menarche.

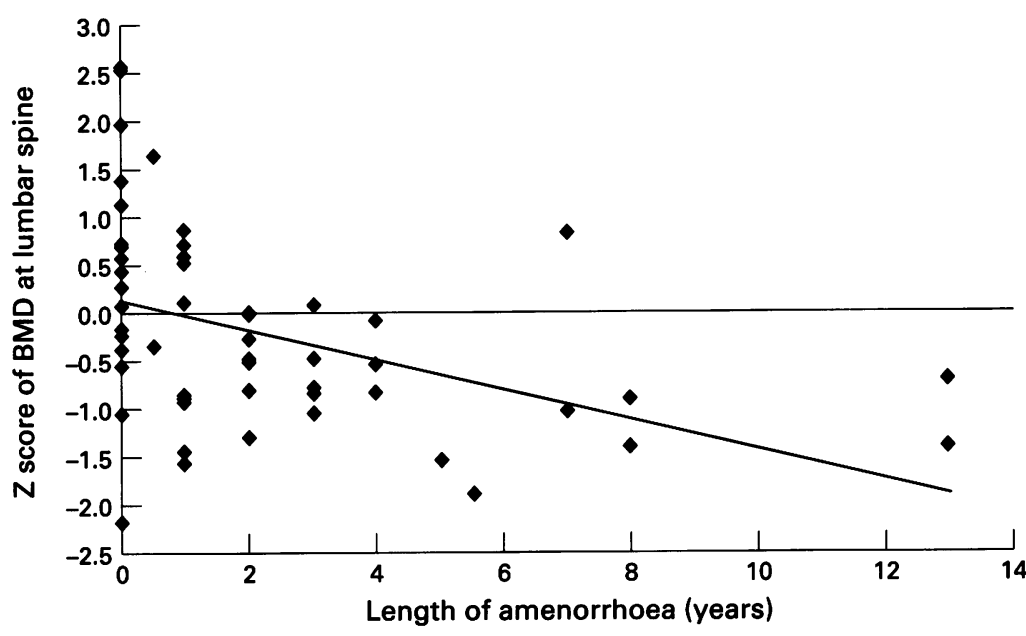

Figure $2 Z$ score of BMD at the lumbar spine plotted against years of amenorrhoea.

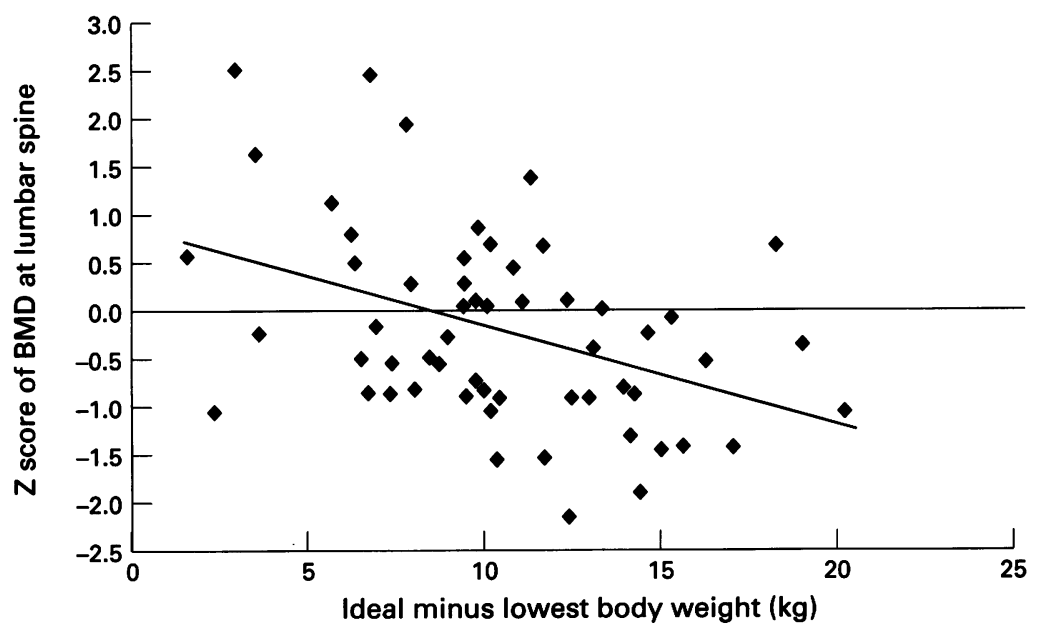

Figure $3 Z$ score of $B M D$ at the lumbar spine plotted against ideal minus lowest body weight.

cant at the femoral neck and was independent of amenorrhoea (correlation 0.33). Ideal body weight was calculated using the formula $\mathrm{BMI}=$ $\mathrm{W} / \mathrm{H}^{2}$, where $\mathrm{BMI}$ (body mass index) was taken as 20 , and $H$ (height) was known from measurement (fig 3).

No significant relationships were found between the following variables: (1) duration of oral contraceptive pill usage and BMD at either the lumbar spine or the femoral neck in either amenorrhoeic or eumenorrhoeic dancers; (2) years of oligomenorrhoea and BMD at either the femoral neck or lumbar spine.

Thus certain variables appear to demonstrate some explanatory power in relation to the $\mathrm{Z}$ score for $\mathrm{BMD}$. In order to quantify whether a particular combination of variables gives an even better explanation of the $Z$ score for BMD, a model of BMD was constructed using multiple regression incorporating the most significant variables that influenced the $Z$ score of $B M D$ at the lumbar spine. The best model included the variables duration of amenorrhoea, ideal minus lowest weight, and age at menarche. The correlation factors between these variables confirmed that they were independent of each other.

In this model, $\mathbf{R}^{2}$ was $33.6 \%$, in other words $33.6 \%$ of the total variation in the $\mathrm{Z}$ score at the lumbar spine could be accounted for by these variables. The regression equation was found to be: $\mathrm{Z}=3.15-0.10 \mathrm{~A}-0.07 \mathrm{~W}-0.17 \mathrm{M}$, where $Z=Z$ score for $B M D$ of the lumbar spine, $A=$ years of amenorrhoea, $W=$ ideal lowest weight, and $M=$ age at menarche. The values of $A, W$, and $M$ for individual dancers can be entered to predict the $Z$ score for the BMD at the lumbar spine.

\section{Discussion}

\section{BMD AND MENSTRUAL PATTERN}

Menarche

A significant negative relationship was found with $\mathrm{BMD}$ at the lumbar spine: the later the age at menarche, the lower the $\mathrm{Z}$ score for $\mathrm{BMD}$. This implies that delayed menarche and any primary amenorrhoea have an important effect on BMD in later life, probably by affecting the attainment of peak bone mass. The importance of peak bone mass on adult BMD has been suggested in review articles, ${ }^{10}{ }^{11}$ and osteopenia has been described in men who experience delayed puberty. ${ }^{12}$ However, no studies to date have found a direct link between age at menarche and $\mathrm{Z}$ score for $\mathrm{BMD}$, so this is a new finding from this study.

\section{Amenorrhoea}

The amenorrhoeic dancers had significantly reduced $B M D$ at the lumbar spine compared with the normal population and with the eumenorrhoeic dancers; however, the BMD at the femoral neck was not significantly reduced. This demonstrates that amenorrhoea in dancers has a greater adverse effect at the lumbar spine than at the femoral neck, suggesting that the former site is more sensitive to the hypo-oestrogenic state of amenorrhoea. The decrease in BMD caused by amenorrhoea was quantified, as the duration of amenorrhoea was found to have a significant negative relationship to $B M D$ at the lumbar spine. Although 33 of the 38 dancers with a history of amenorrhoea had resumed menstruation on average 12.6 years previously, the fact that their lumbar BMD was still reduced suggests a long term effect of amenorrhoea. 
OTHER FACTORS

Dance training

The eumenorrhoeic dancers had significantly increased BMD at the femoral neck compared with both the normal population and amenorrhoeic dancers. This suggests that the femoral neck rather than the lumbar spine is the site that benefits most from the weight bearing nature of dance training. This explains why the amenorrhoeic dancers exhibited reduced BMD at the lumbar spine, but not at the femoral neck. This site specific effect of dance training is consistent with the results of another study. ${ }^{13}$ However, that study involved actively training dancers who demonstrated BMD at the femoral neck above the mean, whereas the majority of dancers in the present study were older and no longer performing. A localised beneficial effect of exercise on the skeleton is found in other types of training. For example, in amenorrhoeic rowers, in which exercise is targeted at the spine, spinal bone loss is attenuated to a level found in sedentary eumenorrhoeic women. ${ }^{14}$ However, once again no study has been conducted on these athletes once training is discontinued.

In summary, the decrease in BMD at the lumbar spine but not at the femoral neck in amenorrhoeic dancers may be explained by the greater sensitivity of the lumbar spine to the hypo-oestrogenic state. Alternatively the femoral neck may be protected from decreases in BMD by virtue of being the major weight bearing site, which is supported by the fact that the eumenorrhoeic dancers had significantly higher BMD at this site. A combination of these two factors probably accounts for the difference in BMD at the femoral neck and lumbar spine.

Although the number of oligomenorrhoeic dancers was small, it is interesting to note that there was a greater proportion of contemporary than classical dancers and that the average BMD at the lumbar spine was greater than that for the femoral neck. Contemporary dancers may be similar to rowers in that their form of exercise is targeted at the spine rather than the femoral neck. Certainly, compared with ballet, in which the back is held very upright, contemporary dance requires far more movement of the spine and far more floor work, in other words less weight bearing exercise focused on the femoral neck.

\section{Weight}

The variable of ideal minus lowest weight had a negative effect on BMD at the lumbar spine, which was independent of amenorrhoea.

\section{Oral contraceptive pill}

The lack of a positive relationship between the pill and BMD is consistent with another study ${ }^{15}$ in which loss of BMD caused by amenorrhoea was not reversible with hormonal treatment. This finding is of concern as it suggests that, once BMD is lost as a consequence of amenorrhoea, hormone replacement treatment in the form of the oral contraceptive pill is not adequate to correct this deficit. However, this aspect needs to be studied prospectively, as in the present study the duration of pill usage (average 2.5 years) was shorter than the duration of amenorrhoea (average 3.5 years). Also it is not possible to say whether the magnitude of the reduction in BMD at the lumbar spine would have been greater without use of the pill.

\section{MODEL OF BMD}

The model of BMD constructed using multiple regression incorporates the variables duration of amenorrhoea, ideal minus lowest body weight, and age at menarche. In this model $\mathrm{R}^{2}$ was $33.6 \%$, in other words $33.6 \%$ of the total variation in the $Z$ score for $B M D$ at the lumbar spine could be accounted for by these factors. This is a potentially important finding since $70 \%$ of the variability of BMD is thought to be genetically determined. Thus the model constructed from the results of this study quantifies the important environmental factors of delayed menarche, duration of secondary amenorrhoea, and low body weight.

\section{FURTHER WORK}

The present study used menstrual recall, which is reasonably reliable in dancers, who are precise people who keep professional engagement diaries. However, a study with a longitudinal design in which the dancers could be followed up would clearly be better. Ideally, a group of dancers would be monitored from the start of their careers.

It would be interesting to study whether exercises targeted at the lumbar spine had a beneficial effect on BMD in this region in amenorrhoeic dancers. This idea is supported by the fact that training appears to have a site specific effect: in dancers on the femoral neck and in rowers, and possibly contemporary dancers, on the lumbar spine.

\section{IMPLICATIONS}

This study suggests that in spite of the vigorous exercise obtained with dance training, associated menstrual disruption has a detrimental effect on BMD at the lumbar spine. However, any loss of BMD at the femoral neck appears to be attenuated by the beneficial effect of previous weight bearing dance training at this site. Therefore in order to prevent the decrease in BMD in this at risk group of exercising women with menstrual disruption, it would be advisable to maximise peak bone mass and minimise subsequent loss. Young dancers can maximise peak bone mass by being vigilant of delayed menarche, primary amenorrhoea, and excessive weight loss, as this study shows that these factors have a significant negative effect on BMD. In order to minimise subsequent loss of BMD, dancers should be vigilant of prolonged episodes of amenorrhoea. It is possible that exercises targeted at the spine may attenuate bone mineral loss at this site in amenorrhoeic dancers. The model of BMD constructed could be used to predict and identify those at risk of low BMD at the lumbar spine, towards whom the above preventive strategies could be targeted. 


\section{Conclusion}

In professional female dancers, delay of menarche and duration of secondary amenorrhoea has a significant negative relationship with BMD at the lumbar spine. Any decrease in BMD at the femoral neck in dancers with a history of amenorrhoea is partially attenuated by virtue of it being the major weight bearing site in dance training, and in eumenorrhoeic dancers $\mathrm{BMD}$ at this site is significantly increased.

Grateful thanks go to Organon Laboratories and Solvay Healthcare for their support of this study.

Compston JE, Cooper C, Kanis JA. Bone densitometry in clinical practice. BMF 1995;310:1507-10.

Wolman RL. Osteoporosis and exercise. BMF 1994;309: 400-3.

3 Drinkwater BL, Nilson $\mathrm{K}$, Chestnut $\mathrm{CH}$, Bremmer WJ Shainholtz S, Southworth MB. Bone mineral content of amenorrhoeic and eumenorrhoeic athletes. $N$ Engl f Med 1984;311: $277-81$.

4 Snow-Harter CM. Bone health and prevention of osteoporosis in active and athletic women. Clin Sports Med oporosis in active
5 Wilson JH, Wolman RL. Osteoporosis and fracture complications in an amenorrhoeic athlete. $\mathrm{Br} f$ Rheumato 1994;33:480-1

6 Drinkwater $\mathrm{BL}$, Nilson $\mathrm{K}$, Chestnut $\mathrm{CH}$. Bone mineral density after resumption of menses in amenorrhoeic athletes $\mathcal{} A M A$ 1986;256:380-2.

7 Jonnavithula S, Warren MP, Fox RP, Lazaro MI. Bone density is compromised in amenorrhoeic women despite return of menses: a 2 year study. Obstet Gynecol 1993;81:669-74

8 Karisson MK, Johnell O, Obrant KJ. Bone mineral density in professional ballet dancers. Bone Miner 1993;21:163-9.

9 Kumar PJ, Clark ML, editors. Clinical medicine. 2nd ed. London: Ballière Tindall, 1990:779.

10 Cooper C, Eastell R. Bone gain and loss in premenopausal women. BMF 1993;306:1357-8

11 Seeman E. Reduced bone density in women with fractures: contribution of low peak bone density and rapid bone loss Osteoporosis International 1994;4(suppl 1):15-25.

12 Finkelstein J, Neer R, Biller B, Crawford J, Klibanski A. Osteopenia in men with a history of delayed puberty. $N$ Engl f Med 1992;326:600-4.

13 Young N, Formica C, Szmukler G, Seeman E. Bone density at weight-bearing sites in ballet dancers: the effects of exercise, hypogonadism and body weight. 7 Clin Endocrino 1994;41:275-81.

14 Wolman R, Clarke P, McNally E, Harries M, Reeve J. Menstrual state and exercise as determinants of spinal trabecular bone density in female athletes. BMF 1990;301:516-18.

15 Guleki B, Davies MC, Jacobs HS. Effect of treatment on established osteoporsis in youg women with amenorrhoea. Clin Endocrinol (Oxf) 1994;41:275-81.

White with blue border and BASM logo - $£ 5+£ 1 \mathrm{p} \& \mathrm{p}$

27-inch square

Navy blue with fringe and BASM logo

$£ 5+£ 1 \mathrm{p} \& \mathrm{p}$

$54 \times 9$ inches (oblong)

Ties Single motif

Multi motif

Blazer badge Wire -4 inches high

$£ 6+£ 1 \mathrm{p} \& \mathrm{p}$

$£ 6+£ 1 \mathrm{p} \& \mathrm{p}$

Wire -3 inches high

$£ 5+£ 1 \mathrm{p} \& \mathrm{p}$

$£ 5+£ 1 \mathrm{p} \& \mathrm{p}$

\section{New stock to order}

Sweaters

Lambswool fine knit, V-neck or round

$£ 32+£ 1 \mathrm{p} \& \mathrm{p}$

neck with small motif. Machine washable.

State colour and chest size required.

Slipovers

Lambswool fine knit, V-neck, with small

$£ 30+£ 1 \mathrm{p} \& \mathrm{p}$

motif. Machine washable. State colour

and chest size required.

Sweatshirts

With small motif.

State colour and chest size required.

Polo shirts

With small motif.

State colour and chest size required.

$£ 20+£ 1 \mathrm{p} \& \mathrm{p}$

$£ 18+£ 1 \mathrm{p} \& \mathrm{p}$

Send orders to John H Clegg JP BSc LDS RCS Eng, Hon Secretary,

Birch Lea, 67 Springfield Lane, Eccleston, St Helens, Merseyside WA10 5HB, UK. (Tel: 01744 28198) 